\section{Molecular interactions between Vestigial and Scalloped promote wing formation in Drosophila}

\author{
Andrew J. Simmonds, ${ }^{1,4}$ Xiaofeng Liu, ${ }^{3,4}$ \\ Kelly H. Soanes ${ }^{2}$ Henry M. Krause, ${ }^{1}$ \\ Kenneth D. Irvine, ${ }^{3}$ and John B. Bell ${ }^{2,5}$
}

\begin{abstract}
${ }^{1}$ Banting and Best Department of Medical Research, Charles H. Best Institute, University of Toronto, Ontario M5G 1L6, Canada; ${ }^{2}$ Department of Biological Sciences, University of Alberta, Edmonton, Alberta T6G 2E9, Canada; ${ }^{3}$ Waksman Institute and Department of Molecular Biology and Biochemistry, Rutgers, The State University, Piscataway, New Jersey 08854 USA
\end{abstract}

Scalloped (Sd) and Vestigial $(\mathrm{Vg})$ are each needed for Drosophila wing development. We show that $\mathrm{Sd}$ is required for $\mathrm{Vg}$ function and that altering their relative cellular levels inhibits wing formation. In vitro, $\mathrm{Vg}$ binds directly to both Sd and its human homolog, Transcription Enhancer Factor-1. The interaction domains map to a small region of $\mathrm{Vg}$ that is essential for $\mathrm{Vg}$-mediated gene activation and to the carboxy-terminal half of Sd. Our observations indicate that $\mathrm{Vg}$ and $\mathrm{Sd}$ function coordinately to control the expression of genes required for wing development, which implies that $\mathrm{Vg}$ is a tissuespecific transcriptional intermediary factor of Sd.

Received August 24, 1998; revised version accepted November 3, 1998

The Drosophila vestigial $(\mathrm{vg})$ and scalloped $(\mathrm{sd})$ genes are expressed in similar patterns during wing development, and mutations in either gene lead to loss of wing tissue (Campbell et al. 1991, 1992; Williams et al. 1991, 1993). $\mathrm{Vg}$ is a developmentally regulated nuclear protein of previously unknown function and is required principally for the development of the wing and haltere (Williams et al. 1991). Sd is part of a highly conserved family of transcription factors, the TEA/ATTS domain proteins and is an essential protein with a wider developmental role (Campbell et al. 1991, 1992).

Expression of $v g$ in cells of the developing wing primordia is established by a number of conserved signaling pathways and is required for subsequent cell proliferation and patterning. Expression of wingless (wg), as well as interactions between dorsal and ventral cells that activate the Notch receptor, initially directs limited $v g$ expression along the dorsal-ventral $(\mathrm{D} / \mathrm{V})$ wing boundary (Williams et al. 1994; Kim et al. 1995, 1996; for review,

[Key Words: Vestigial; Scalloped; Wing; Drosphila; transcription; development]

${ }^{4}$ These authors made equal contributions to this work.

${ }^{5}$ Corresponding author.

E-MAIL jbell@gpu.srv.ualberta.ca; FAX (403) 492-9234. see Irvine and Vogt 1997). Subsequent $v g$ expression in the wing primordia occurs in response to both the $\mathrm{D} / \mathrm{V}$ Wg signal and Decapentaplegic (Dpp), a member of the Transforming Growth Factor- $\beta$ (TGF- $\beta$ ) protein family, secreted by cells along the anterior-posterior $(\mathrm{A} / \mathrm{P})$ border. (Blair 1994; Kim et al. 1996, 1997; Zecca et al. 1996; Neumann and Cohen 1997). By the late third larval instar, maximal amounts of $\mathrm{Vg}$ are seen in cells at the $\mathrm{D} / \mathrm{V}$ wing disc boundary, whereas cells located farther from this border produce progressively less Vg (Williams et al. 1991). $v g$ is also required to maintain $s d$ expression in the wing progenitor cells, and $s d$ is similarly required for the maintenance of elevated $v g$ expression (Williams et al. 1993).

A cellular role for $\mathrm{Sd}$ can be inferred from studies of its human homolog Transcription Enhancer Factor-1 (TEF1). TEF-1 binds to SV40 enhancer sequences via a TEA/ ATTS class DNA-binding domain, and has been shown to require transcriptional intermediary factors (TIFs) for proper function (Xiao et al. 1991; Ishiji et al. 1992; Hwang et al. 1993; Gupta et al. 1997). Interestingly, it has been reported that the Sd TEA/ATTS domain does not bind the same enhancer DNA sequences in vitro as TEF-1, although TEF-1 can substitute for Sd during Drosphila wing development (Hwang et al. 1993; Deshpande et al. 1997). This suggests that other factors within Drosphila wing cells interact with and modify the specificity of both Sd and TEF-1 in a similar fashion.

\section{Results and Discussion}

Previous analysis has shown that ectopic expression of $\mathrm{Vg}$, under control of a $d p p$ enhancer, can induce transformation of some cells in the eye, antenna, leg, and genital imaginal discs into wing-specific fates, as well as causing tissue overgrowth (Fig. 1b; Kim et al. 1996). Importantly, whereas Vg expression is normally restricted to the wing and haltere imaginal discs, a subset of cells within almost all imaginal discs normally express $s d$ (Campbell et al. 1992). Thus, when Vg is ectopically produced a supply of Sd is already present in those tissues. As $\mathrm{Sd}$ is required for formation of the normal wing, we tested whether there is a similar requirement for Sd in the formation of Vg-induced ectopic wings. The induction of wing tissue overgrowths by ectopic Vg was partially suppressed in animals heterozygous for a strong viable allele of $s d$ (Fig. 1d), $s d^{58}$, and was completely suppressed in $s d^{58}$ hemizygotes (Fig. 1e). These observations demonstrate that $\mathrm{Vg}$ requires Sd to transform cells to wing fates. This requirement does not appear to reflect a role for $\mathrm{Sd}$ as a downstream effector of $\mathrm{Vg}$ function, as expression of Sd alone, whether under the control of $d p p$ or other promoters, does not induce the formation of ectopic wing tissue (Fig. 1c; data not shown). Instead, these observations suggest that $\mathrm{Sd}$ and $\mathrm{Vg}$ could act in parallel to induce wing cell fates.

The possibility that coordinate action of $\mathrm{Sd}$ and $\mathrm{Vg}$ is effected via a direct protein-protein interaction was ex- 


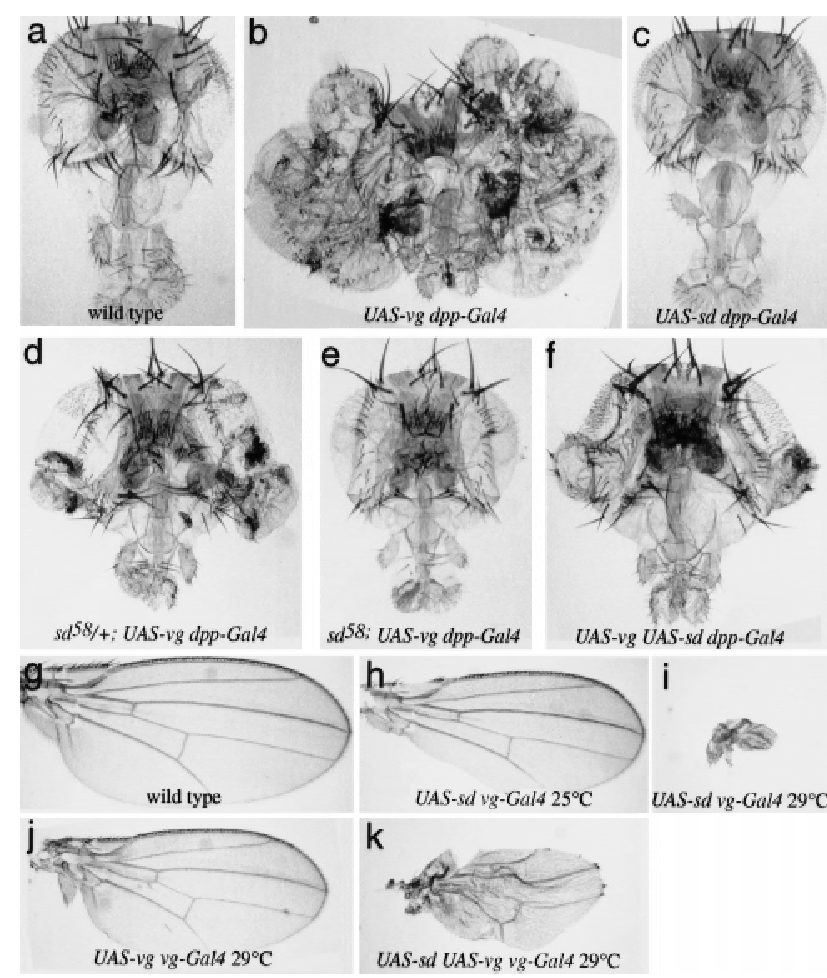

Figure 1. Vg requires $\mathrm{Sd}$ and is sensitive to $\mathrm{Sd}$ levels in vivo. (a-f) Drosphila heads; $(g-k)$ Drosphila wings, in which the Vg and/or Sd proteins have been ectopically expressed using the UAS-Gal4 system (Brand and Perrimon 1993). (a) Wild type. (b) $U A S-v g d p p-G A L 4$. A massive outgrowth of wing tissue from the eye occurs. (c) UAS-sd dpp-GAL4. No wing tissue is induced, and higher levels of expression (e.g., using ptc-GAL4) result in loss of head tissue. (d) $s d^{58} /+; U A S-v g d p p-G A L 4$. The $s d^{58}$ mutation reduces the amount of Sd produced, and formation of ectopic wing tissue is partially suppressed. $(e) s d^{58}$; UAS$v g d p p-G A L 4$. The formation of wing tissue is completely suppressed when no wild-type copy of $s d$ is present. (f) $U A S-v g$ $U A S-s d d p p-G A L 4$. The formation of wing tissue is also partially suppressed when levels of Sd are increased. Raising or lowering the levels of Sd relative to that of $\mathrm{Vg}$ within the developing wing disc produces corresponding phenotypes. $(g)$ Wild type. (h) UAS-sd vg-GAL4 at $25^{\circ} \mathrm{C}$. Elevating Sd levels in wing progenitor cells leads to incomplete formation of the wing margin. (i) UAS-sd $v g-G A L 4$ at $29^{\circ} \mathrm{C}$. This effect becomes more severe in flies raised at $29^{\circ} \mathrm{C}$, where almost no wing tissue is formed. (j) UAS-Vg vg-GAL4 at $29^{\circ} \mathrm{C}$. The elevated Vg levels in the wings of these animals leads to a slight reduction in wing size. (k) UAS-sd UAS-vg vg-GAL4 at $29^{\circ} \mathrm{C}$. The loss of wing tissue induced by excess $\mathrm{Sd}(i)$ is partially suppressed by the simultaneous increase in $\mathrm{Vg}$ expression.

amined by in vitro-binding experiments. Microaffinity columns bound with bacterially expressed Sd protein selectively retain in vitro-translated Vg (Fig. 2a). Similarly, $\mathrm{Vg}$ columns show specific retention of Sd (Fig. 2b). TEF1 , the vertebrate homolog of Sd, was retained on Vg columns with similar affinity (Fig. 2b). Control columns containing the homeodomain proteins Engrailed (En) and Fushi tarazu (Ftz; not shown) did not retain Vg or Sd. Additionally, Luciferase (Luc) did not bind to Vg or Sd columns, confirming that the $\mathrm{Sd}-\mathrm{Vg}$ interaction is spe- cific (Fig. 2a-c). Notably, neither $\mathrm{Vg}$ nor Sd bound to themselves either, suggesting that they do not form homomultimers (Fig. 2a,b).

To map Vg-Sd and Vg-TEF-1 interaction domains, a Far Western blotting assay was used to screen 15 deleted proteins that remove terminal or internal regions of $\mathrm{Vg}$ (Fig. 3a-c). Only Vg proteins that contain amino acids 279-335 have any significant affinity for Sd (Fig. 3b,c). The Vg-Sd interaction appears to be limited to this 56amino-acid domain, as Sd does not bind to a deleted Vg protein missing only these amino acids, and a construct encoding only this portion of the protein will still bind to Sd. Significantly, a duplicate panel of Vg deletion proteins probed with TEF-1 (Fig. 3b,c) shows that TEF-1 interacts with $\mathrm{Vg}$ via the same protein domain. Affinity columns containing this protein fragment of $\mathrm{Vg}$ bind $\mathrm{Sd}$ and TEF-1 protein as well as full-length Vg does (Fig. 2c). This Sd/TEF-1-binding domain of $\mathrm{Vg}$ is serine rich and includes putative phosphorylation sites (Williams et al. 1991). Phosphorylation of Vg at these sites may potentially modify the $\mathrm{Vg}-\mathrm{Sd}$ interaction. This region is highly conserved in Vg proteins from Drosphila virilis (Fig. 3d) and Aedes aegypti (S. Carroll, pers. comm.). Similar sequences also occur in mammalian genomic and expressed sequence tag databases (Fig. 3d). The amino- and carboxy-terminal portions of Sd were also tested to map which region of Sd interacts with Vg. Previous studies with TEF-1 demonstrated that regions mediating interaction with cell-specific TIFs were separable from the DNA-binding TEA/ATTS domain (Xiao et al. 1991). The Vg-binding region of Sd maps to the carboxy-terminal half of the protein, separable from the TEA/ATTS domain in the amino-terminal half (Fig. 3e). The carboxyterminal portion of $\mathrm{Sd}$ is also highly similar to TEF-1 (Campbell et al. 1992; Hwang et al 1993; Despande et al.

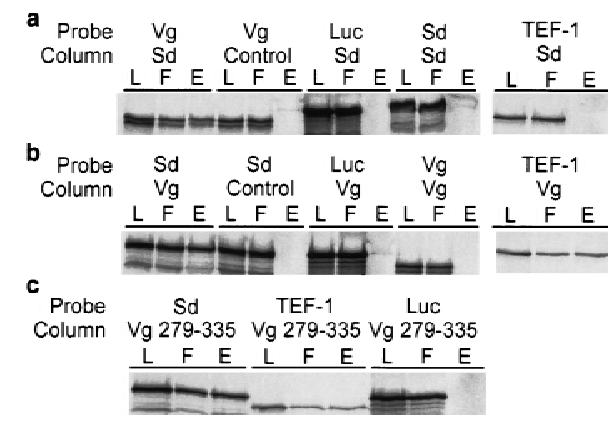

Figure 2. Vg and Sd exhibit a strong protein-protein interaction in vitro. (a) Affinity chromatography was performed using bound bacterially expressed Sd protein [(L) column load; (F) column flowthrough; (E) column eluate]. Sd columns selectively retain Vg and not Sd or TEF-1. As a control for nonspecific binding, Luc was expressed in the same in vitro system and shown to not bind to the Sd column. Similarly, the column matrix alone does not retain significant amounts of labeled $\mathrm{Vg}$. (b) Vg columns specifically bind Sd protein but not Vg or Luc. The human TEF-1 protein, a homolog of Drosphila Sd, also shows a similar specific affinity for $\mathrm{Vg}$. (c) Affinity columns bound with a protein consisting of Vg amino acids 279-335 (see Fig. 3) can selectively retain Sd or TEF-1 but not Luc. 


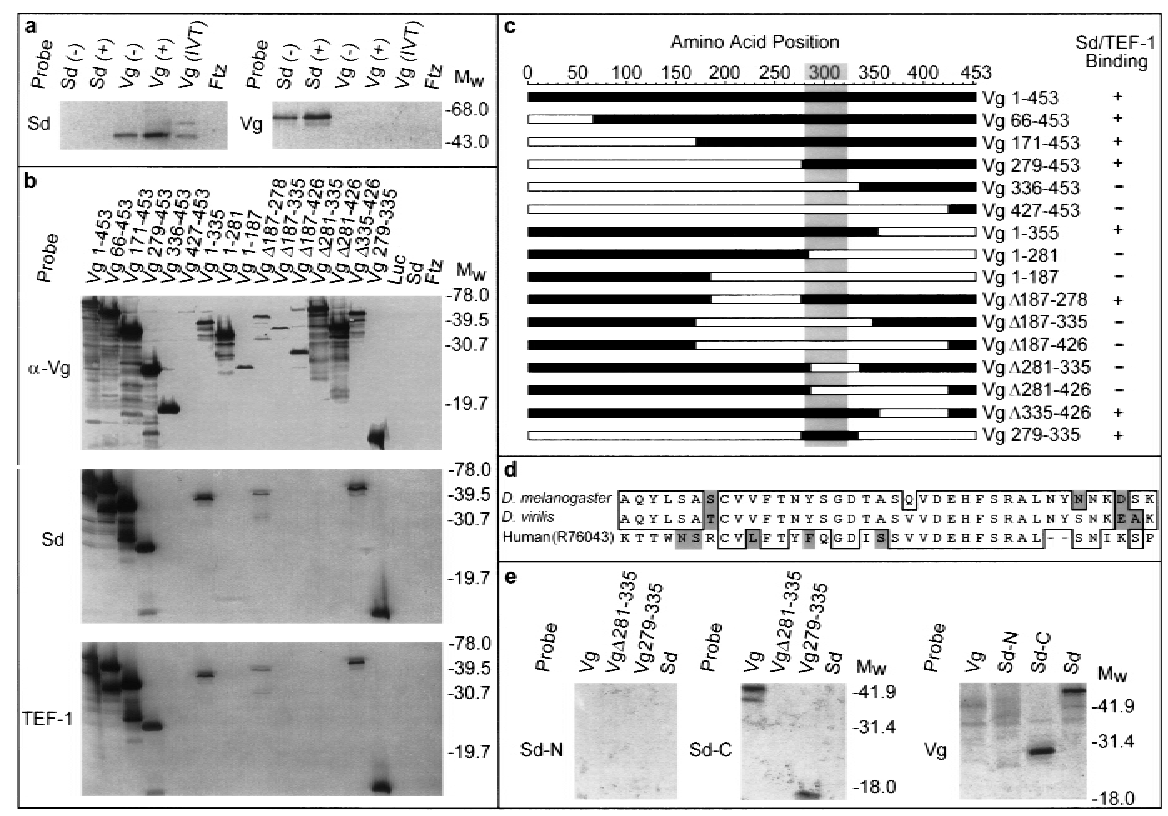

Figure 3. Mapping the Vg-Sd interaction domain. (a) Far Western blots of bacterial or in vitro-translated (IVT) Vg or Sd were probed with labeled Vg or Sd probes. Ftz protein expressed under similar conditions was also included on each blot to detect nonspecific probe binding. Sd selectively binds bacterially produced and IVT Vg, whereas a corresponding blot probed with $\mathrm{Vg}$ shows binding only to Sd. As the detected band is more intense in cell extracts after induction $(+)$ of the expression plasmid than before $(-)$, this confirms that each is plasmid and not endogenously encoded. $(b)$ All but one of the specific deletions of $\mathrm{Vg}(c)$ were recognized by anti- $\mathrm{Vg}$ antibody $(\alpha-\mathrm{Vg})$, confirming that $\mathrm{Vg}$ is present in each lane. Expression of the Vg 427-453 protein was verified by Coomassie staining. When these deleted proteins were probed with Sd or TEF-1 under conditions similar to those above, only proteins retaining amino acids 279-335 of Vg were detected. Luc, Sd, or Ftz control lanes did not show any signals. (c) A map summarizing the position and relative size of the deletions (open bars) within Vg assayed for binding (+ or - ) to Sd or TEF-1. The shaded area denotes a region that is highly similar to $\mathrm{Vg}$ from $D$. virilis and $A$. aegypti (S. Carroll, pers. comm.). (d) This region is also highly similar to sequences identified in mammalian genomic and expressed sequence tag databases (GenBank/EST accession nos. Z798880, Z97632, AA474871, AA571483, W81241, R65857, R73306, $\mathrm{R} 76043)$. In addition to the 38 amino acids indicated, the smallest tested portion of $\mathrm{Vg}$ that has Sd-binding ability includes an amino-terminal Q and amino acids (ESSSPMSSRNFPPSFWN) carboxy-terminal to this homologous region. (e) Probes corresponding to the amino-terminal half of Sd (amino acids 1-242, Sd-N) show no interaction with Vg. The carboxy-terminal half of Sd (amino acids 240-440, Sd-C) binds to Vg protein containing only amino acids 279-335 (Sd-binding domain). A reciprocal blot using full-length $\mathrm{Vg}$ (Vg) as a probe shows interaction only with the carboxy-terminal half of Sd (Sd-C).

1997), which is consistent with the observation (Fig. 3c) that TEF-1 binds to Vg with the same affinity as Sd does. To confirm the direct protein-protein interaction between $\mathrm{Vg}$ and $\mathrm{Sd}$ in a cellular environment, a yeast twohybrid assay was used. In yeast, Vg and Sd proteins show a specific and reciprocal interaction when fused to either Gal4-binding domain (pGBDU) or Gal4 activation domain (pACT) fusion constructs (not shown; James et al. 1996). Each construct alone or paired with nonspecific (pSNF1BD) bait sequences does not activate a lacZ reporter.

We employed the UAS-Gal4 system (Brand and Perrimon 1993) to further examine the in vivo significance of the $\mathrm{Sd}-\mathrm{Vg}$ interaction. As $v g$ is normally required for $s d$ expression in wing imaginal discs (Williams et al. 1993), we examined the influence of ectopic Vg expression on $s d$. Normally, $s d$ expression appears confined to the wing pouch region of the wing imaginal disc, although very low levels can sometimes be detected elsewhere. Strong $s d$ expression is induced outside of the wing pouch in wing disc cells where $v g$ is expressed ectopically under the control of the patched (ptc) promoter (UAS-vg ptc-GAL4) (Fig. 4 a-d). Activation of a downstream target gene by ectopic expression of $\mathrm{Vg}$ and Sd was observed using expression of the cut (ct) gene as an assay. ct is likely a direct $\mathrm{Vg}-\mathrm{Sd}$ target in Drosphila, as $s d, v g$, and $c t$ interact genetically, and the Sd TEA/ATTS domain has been shown to bind to $c t$ wing margin enhancer DNA sequences (Morcillo et al. 1996). Consistent with our observation of ectopic $s d$ expression and the hypothesis that $\mathrm{Sd}$ and $\mathrm{Vg}$ function coordinately to regulate gene expression, ectopic expression of $\mathrm{Vg}$ in the wing under ptc-GAL4 control also produces activation of $c t$ (Fig. 4e). However, when a $U A S-V g$ construct that is missing the 56-amino-acid $\mathrm{Sd}$ binding domain is expressed, $s d$ and $c t$ are not induced (Fig. 4g,h). Thus, activation of both target genes, $s d$ and $c t$, by $\mathrm{Vg}$ requires the $\mathrm{Sd}-\mathrm{Vg}$ interaction domain identified in vitro, implying that this is Sd dependent. Moreover, the UAS-Vg construct with the Sd-binding domain deleted is also unable to induce the formation of ectopic wing tissue (results not shown), consistent with the observation that this induction is $s d$ dependent (Fig. 1e). Interestingly, Vg protein deleted for the Sdbinding domain is found in the cytoplasm rather than in the nucleus (Fig. 4f), which implies that association with $\mathrm{Sd}$ is required for nuclear localization of $\mathrm{Vg}$.

Further support of a direct $\mathrm{Sd}-\mathrm{Vg}$ interaction in vivo comes from the observation that elevated amounts of Sd protein can also result in programmed cell death and wing tissue loss (Fig. 1g-i; data not shown). These phenotypes are very similar to those of $s d$ or $v g$ loss-of-function mutants (Williams et al. 1991, 1993; Campbell et al. 1992). The apparent dominant-negative effect of Sd overexpression suggests that a Vg-Sd heterodimer is functional in vivo and that Sd alone can compete with the functional heterodimer for binding to DNA or other essential cofactors. This suggestion is consistent with studies of the transcriptional activity of TEF-1 and Sd in 

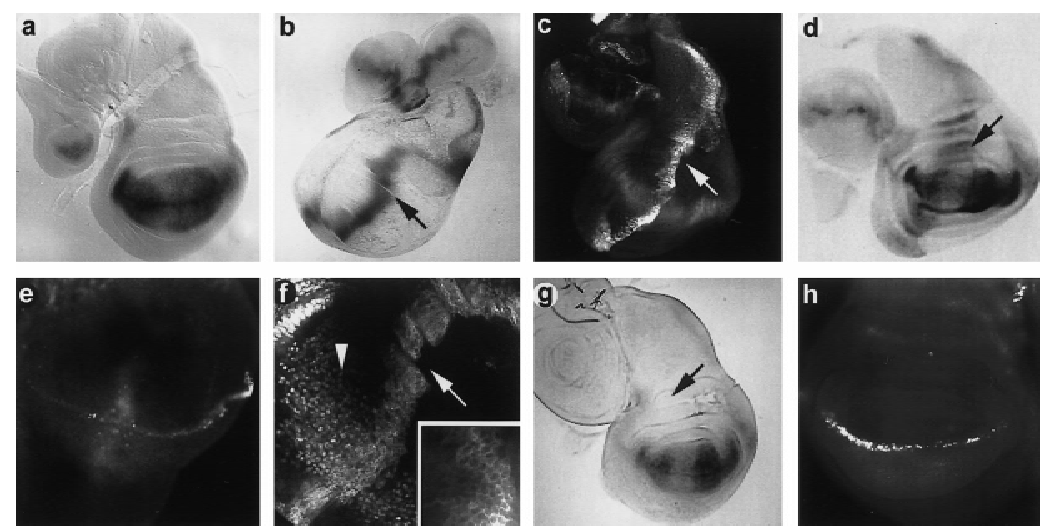

Figure 4. Influence of ectopic $\mathrm{Vg}$ on gene expression. (a) Third instar larval wing discs of genotype $s d-l a c Z$; ptc-GAL4 showing a normal pattern of high levels of $s d-1 a c Z$ expression in all cells of the presumptive wing pouch (Campbell et al. 1992). Using in situ hybridization to $s d$ mRNA, low levels of $s d$ expression are also detected outside of the wing pouch (not shown). A localized depression of $s d$ activity is usually seen where the $\mathrm{D} / \mathrm{V}$ intersects the $\mathrm{A} / \mathrm{P}$ boundary. (b) ptc-GAL4 activates a UAS-lacZ reporter along the $\mathrm{A} / \mathrm{P}$ axis of the wing disc. Note that the highest levels of activation occur in cells immediately adjacent to the border (arrow); lower levels of lacZ expression are seen in more anterior cells. (c) A ptc-GAL4; UAS-vg wing imaginal disc shows a similar graded pattern of ectopic $v g$ expression along the A/P margin (arrow). (d) Third instar wing discs of genotype $s d-l a c Z$; ptc-GAL4; UAS-vg. The ectopic vg expression activates $s d$ along the $\mathrm{A} / \mathrm{P}$ margin, causing a nongraded level of activation of the $s d-l a c Z$ reporter gene in $v g$-expressing cells (arrow). (e) A wing imaginal disc of the same genotype as $c$ stained with anti-ct antibody. Ectopic activation of $c t$ occurs in some cells that express ectopic $\mathrm{Vg}$ and $\mathrm{Sd}$ along the $\mathrm{A} / \mathrm{P}$ margin. (f) $\mathrm{Vg} \Delta 281-335$ protein (driven by ptc-GAL4) is found primarily in the cytoplasm [arrow and inset (high magnification)] compared to the nuclear localization of endogenous wild-type $\mathrm{Vg}$ (arrowhead). ( $g$ ) In discs containing $s d-l a c Z$, ptc-GAL4 mediated expression of a UAS-vg $\Delta 281-335$ construct (missing the Sd-binding domain) does not induce $s d$ expression along the A/P margin (arrow).

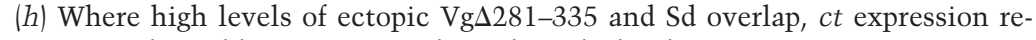
mains in the wild-type pattern along the $\mathrm{D} / \mathrm{V}$ border.

cultured cell lines, in which dominant-negative effects (squelching) appear to occur when they are overexpressed (Xiao et al. 1991; Ishiji et al. 1992; Hwang et al. 1993; Halder et al. 1998). Direct in vivo support for this hypothesis comes from the observation that overexpression of Sd is able to suppress the consequences of ectopic $\mathrm{Vg}$ expression almost as efficiently as loss of $s d$ function (Fig. 1f). Moreover, overexpression of Vg in the wing is able to partially suppress the tissue loss otherwise associated with Sd overexpression (Fig. 1, cf. k and i). Together, these observations argue that balanced levels of $\mathrm{Sd}$ and $\mathrm{Vg}$ are essential for normal wing development and further support the conclusion that the specific interaction between $\mathrm{Vg}$ and Sd identified in vitro is essential for function in vivo. The exquisite sensitivity of wing tissue growth to the $\mathrm{Sd} / \mathrm{Vg}$ ratio also raises the possibility that variation of this balance could be a mechanism of growth control during normal development.

A wide variety of studies have suggested that TEA/ ATTS domain proteins require tissue-specific TIFs, although relatively little progress has been made toward identifying and characterizing these TIFs (Xiao et al. 1987, 1991; Ishiji et al. 1992; Hwang et al. 1993; Chen et al. 1994; Farrance and Ordahl 1996; Gavrias et al. 1996; Jacquemin et al. 1996; Stewart et al. 1996; Gupta et al. 1997). According to the definitions established by the analysis of TEF-1 (Xiao et al. 1987, 1991; Ishiji et al. 1992), a TIF for Sd would be expected to bind directly to $S d$, to show a restricted pattern of expression, and to be required for Sd function in vivo. Previous studies have shown that $s d$ and $v g$ have similar mutant phenotypes and patterns of expression in the developing wing (Williams et al. 1991; Kim et al. 1996, 1997). The results presented here demonstrate that Sd and Vg proteins bind to each other and that the cooperative action of $\mathrm{Sd}$ and $\mathrm{Vg}$ is required in vivo for Drosphila wing development. These observations, together with the analysis of the coordinate regulation of downstream target genes by Sd and $\mathrm{Vg}(\mathrm{Hal}-$ der et al. 1998), argue that Vg functions as a tissue-specific TIF for Sd. Although it is possible that $\mathrm{Vg}$ interacts with proteins other than $\mathrm{Sd}$, genetic studies argue against this, because all $v g$ mutant phenotypes are shared by $s d$. In contrast, $s d$ is required for the development of other tissues in which $v g$ is not required (Campbell et al. 1991; Williams et al. 1991). Thus, it is likely that there are other trans-acting factors in Drosphila that interact with $\mathrm{Sd}$.

Although the DNA target sequence of Sd is as yet uncharacterized, one target of a yeast TEA/ATTS domain protein (TEC-1) is an element in the TEC-1 promoter (Madhani and Fink 1997). Likewise, in flies, one target of $\mathrm{Sd}-\mathrm{Vg}$ is likely to be the $s d$ promoter itself, as activation of $s d$ during early development is dependent on $\mathrm{Vg}$ (Williams et al. 1993), and ectopic Vg induces elevated expression of $s d$ (Fig. 4). This suggests a model whereby low levels of Sd expression within wing imaginal discs are elevated in the presence of Vg by positive autoregulation. The dependence of elevated levels of $\mathrm{Vg}$ in the wing disc on $s d$ suggests that $v g$ is also a target of positive autoregulation, and direct evidence for this now been obtained (Halder et al. 1998).

The TEA/ATTS domain protein family is involved in developmental processes as diverse as mammalian neuronal and cardiac muscle development (Chen et al. 1994; Jacquemin et al. 1996; Yockey et al. 1996) to conidial formation in Aspergillus (Gavrias et al. 1996) and pseudohyphal growth of Saccharomyces cerevisiae (Madhani and Fink 1997). Although Vg homologs have not yet been identified in these organisms, we have found that genes containing sequences related to the Sd/TEF-1 interaction domain of $\mathrm{Vg}$ are conserved in mammals; these genes are thus candidate TIFs for mammalian TEF-1-related proteins (Fig. 3). One of these candidate TIFs is expressed in fetal heart tissue, which is intriguing given that gene-targeted mutations in TEF-1 result in cardiac defects (Chen et al. 1994). Future challenges will be to 
determine whether genes encoding these putative Sd-interacting domains actually function as TIFs for TEF-1 or related proteins, and whether distinct regulatory TIFs have evolved that adapt the transcriptional activities of conserved Sd/TEF-1 homologs to specific functions in different tissues in their respective organisms.

\section{Materials and methods}

For the in vitro protein interaction assays, PCR fragments containing either full-length $s d$ or $v g$ coding region were cloned into pET16b (Novagen) and expressed in Escherichia coli (BL21-DE3 pLysE) to produce 6x His-tagged Vg or Sd protein. Inverse PCR, using primers that amplified specific portions of the $v g$ or $s d$ coding region shown in Figure 3, was used to create deleted $\mathrm{Vg}$ and Sd expression constructs. Recombinant proteins containing the amino-terminal histidine tag were purified on $\mathrm{Ni}^{2+}$ resin following the manufacturer's directions (Invitrogen). Affinity chromatography, Western, and Far Western blotting were performed as described previously (Guichet et al. 1997), with the following modifications. For microcolumn affinity chromatography, $500 \mu \mathrm{l}$ of a $200 \mu \mathrm{g} / \mathrm{ml}$ solution of each protein to be tested was coupled to $100 \mu \mathrm{l}$ of $\mathrm{Ni}^{2+}$ resin in binding buffer $\left(20 \mathrm{~mm} \mathrm{NaH}_{2} \mathrm{PO}_{4}\right.$ at $\left.\mathrm{pH} 7.8,0.5 \mathrm{M} \mathrm{NaCl}\right)$ and rewashed according to the manufacturer's directions (Invitrogen). Columns with $\mathrm{Ni}^{2+}$ resin alone served as controls for nonspecific binding of the labeled probe. Each column was then equilibrated in $100 \mathrm{~mm} \mathrm{NaCl}, 0.1 \mathrm{~m}$ Tris $(\mathrm{pH} 7.6)$, and $10 \%$ glycerol. Columns were subsequently blocked using a solution of $0.5 \%$ skim milk powder in equilibrium solution. ${ }^{35} \mathrm{~S}$-Labeled probes were made by cloning the relevant coding region of each protein to be tested into pBluescript SK(-) and then expressed using the TnT in vitro-coupled rabbit reticulocyte system (Promega). The resulting probes were purified using Sepharose G25 spin columns, and a 2-ul aliquot of each was then quantified using a PhosphorImager. Approximately $40-45 \mu \mathrm{l}$ of each labeling reaction was combined with $80 \mu$ of blocking solution and passed over the respective affinity column. Any bound protein was eluted using $100 \mu \mathrm{l}$ of the equilibration solution plus 2\% SDS. For Far Western blotting, $\sim 10 \mu \mathrm{l}$ of total lysate from bacteria expressing $\mathrm{Vg}$, $\mathrm{Sd}$, or control protein per lane was separated on a $13 \%$ SDS-polyacrylamide gel and blotted to nitrocellulose. Proteins on the resulting blot were serially renatured in a series of $6,3,1$, and $0.1 \mathrm{M}$ guanidine- $\mathrm{HCl}$ solutions containing $20 \mathrm{~mm}$ Tris ( $\mathrm{pH} 7.6), 100 \mathrm{~mm} \mathrm{NaCl}, 0.1 \%$ Tween $20,2 \%$ skim milk powder, $10 \%$ glycerol, and $1 \mathrm{~mm}$ EDTA. Probes prepared as described were incubated with each blot for $2 \mathrm{hr}$ at $4^{\circ} \mathrm{C}$ in blocking solution plus 1 mм DTT. Antibody staining of imaginal discs was performed as described previously (Simmonds et al. 1995). Rabbit anti-Vg was used at a dilution of $1 / 50$ on imaginal discs and at $1 / 200$ for Western blotting (Williams et al. 1991). Mouse anti- $\beta$-galactosidase (Promega) and mouse anti-Ct 2B10 (Blochlinger et al. 1990) were used at 1/500. sd-lacZ refers to the $s d^{E T X 4}$ line described by Campbell et al. (1992). UAS-sd and UAS$v g \Delta 281-335$ transgenes were constructed by cloning a $2.05-\mathrm{kb}$ XmnIClaI fragment of a $s d$ cDNA (Campbell et al. 1992) or a PCR fragment consisting of the coding region of the $\mathrm{Vg} \Delta 281-335$ expression construct into pUAST (Brand and Perrimon 1993).

\section{Acknowledgments}

We thank Sean Carroll for communication of results prior to publication. A.J.S. was supported by the Alberta Heritage Foundation for Medical Research (AHMFR) and a Charles H. Best postdoctoral fellowship. Research in the laboratory of J.B.B. is supported by the Natural Sciences and Engineering Research Council (NSERC) of Canada. Research in K.D.I.'s laboratory was supported by a grant from the New Jersey Commission on Cancer Research. The anti-Ct 2B10 antibody was obtained from the Developmental Studies Hybridoma Bank (University of Iowa). We acknowledge Garry Ritzel for the yeast two-hybrid assays, Shelagh Campbell and Sarah Hughes for suggestions and critical reading of this manuscript, and Shelagh Campbell, Arthur Chovnick, Sean Carroll, I. Davidson, and P. Chambon for reagents.

The publication costs of this article were defrayed in part by payment of page charges. This article must therefore be hereby marked 'advertise- ment' in accordance with 18 USC section 1734 solely to indicate this fact.

\section{References}

Blair, S.S. 1994. A role for the segment polarity gene shaggy-zeste white 3 in the specification of regional identity in the developing wing of Drosphila. Dev. Biol. 162: 229-244.

Blochlinger, K.R., R. Bodmer, L.Y. Jan, and Y.N. Jan. 1990. Patterns of expression of cut, a protein required for external sensory organ development in wild type and mutant Drosphila embryos. Genes \& Dev. 4: 1322-1331.

Brand, A.H. and N. Perrimon. 1993. Targeted gene expression as a means of altering cell fates and generating dominant phenotypes. Development 118: 401-415.

Campbell, S.D., A. Duttaroy, A.L. Katzen, and A. Chovnick. 1991. Cloning and characterization of the scalloped region of Drosphila melanogaster. Genetics 127: 367-380.

Campbell, S.D., M. Inamdar, V. Rodrigues, V. Raghavan, M. Palazzolo, and A. Chovnick. 1992. The scalloped gene encodes a novel, evolutionarily conserved transcription factor required for sensory organ differentiation in Drosphila. Genes \& Dev. 6: 367-379.

Chen, Z., G.A. Friedrich, and P. Soriano. 1994. Transcriptional enhancer factor 1 disruption by a retroviral gene trap leads to heart defects and embryonic lethality in mice. Genes \& Dev. 8: 2293-2301.

Deshpande, N., A. Chopra, A. Rangarajan, L.S. Shashidhara, V. Rodrigues, and S. Krishna. 1997. The human transcription enhancer factor-1, TEF-1, can substitute for Drosphila scalloped during wingblade development. J. Biol. Chem. 272: 10664-10668.

Farrance, I.K. and C.P. Ordahl. 1996. The role of transcription enhancer factor-1 (TEF-1) related proteins in the formation of M-CAT binding complexes in muscle and non-muscle tissues. I. Biol. Chem. 271: 8266-8274.

Gavrias, V., A. Andrianopoulos, C.J. Gimeno, and W.E. Timberlake. 1996. Saccharomyces cerevisiae TEC1 is required for pseudohyphal growth. Mol. Microbiol. 19: 1255-1263.

Guichet, A., J.W. Copeland, M. Erdelyi, D. Hlousek, P. Zavorszky, J. Ho, S. Brown, A. Percival-Smith, H.M. Krause, and A. Ephrussi. 1997. The nuclear receptor homologue Ftz-F1 and the homeodomain protein Ftz are mutually dependent cofactors. Nature 385: 548-552.

Gupta, M.P., C.S. Amin, M. Gupta, N. Hay, and R. Zak. 1997. Transcription enhancer factor 1 interacts with a basic helix-loop-helix zipper protein, Max, for positive regulation of Cardiac a-myosin heavy-chain gene expression. Mol. Cell. Biol. 17: 3924-3936.

Halder, G., P. Polaczyk, M.E. Kraus, A. Hudson, J. Kim, A. Laughon, and S. Carroll. 1998. The Vestigial and Scalloped proteins act together to directly regulate wing-specific gene expression in response to signaling proteins. Genes \& Dev. (this issue).

Hwang, J.J., P. Chambon, and I. Davidson. 1993. Characterization of the transcription activation function and the DNA binding domain of transcriptional enhancer factor-1. EMBO J. 12: 2337-2348.

Irvine, K.D. and T.F. Vogt. 1997. Dorsal-ventral signaling in limb development. Curr. Opin. Cell Biol. 9: 867-876.

Ishiji, T., M.J. Lace, S. Parkkinen, R.D. Anderson, T.H. Haugen, T.P. Cripe, J.H. Xiao, I. Davidson, P. Chambon, and L.P. Turek. 1992 Transcriptional enhancer factor (TEF)-1 and its cell-specific co-activator activate human papillomavirus-16 E6 and E7 oncogene transcription in keratinocytes and cervical carcinoma cells. EMBO $\mathrm{J}$. 11: 2271-2281.

Jacquemin, P., J.J. Hwang, J.A. Martial, P. Dolle, and I. Davidson. 1996. A novel family of developmentally regulated mammalian transcription factors containing the TEA/ATTS DNA binding domain. J. Biol. Chem. 271: 21775-21785.

James, P., J. Halladay, and E.A. Craig. 1996. Genomic libraries and a host strain designed for highly efficient two-hybrid selection in yeast. Genetics 144: 1425-1436.

Kim, J., K.D. Irvine, and S.B. Carroll. 1995. Cell recognition, signal induction, and symmetrical gene activation at the dorsal-ventral boundary of the developing Drosphila wing. Cell 82: 795-802.

Kim, J., A. Sebring, J.J. Esch, M.E. Kraus, K. Vorwerk, J. Magee, and S.B. Carroll. 1996. Integration of positional signals and regulation of wing formation and identity by Drosphila vestigial gene. Nature 382: 133138. 
Kim, J., K. Johnson, H.J. Chen, S. Carroll, and A. Laughon. 1997. Drosphila Mad binds to DNA and directly mediates activation of vestigial by Decapentaplegic. Nature 388: 304-308.

Madhani, H.D. and G.R. Fink. 1997. Combinatorial control required for the specificity of yeast MAPK signaling. Science 275: 1314-1317.

Morcillo, P., C. Rosen, and D. Dorsett. 1996. Genes regulating the remote wing margin enhancer in the Drosphila cut locus. Genetics 144: $1143-1154$.

Neumann, C.J. and S.M. Cohen. 1997. Long-range action of Wingless organizes the dorsal-ventral axis of the Drosphila wing. Development 124: $871-880$.

Simmonds, A.J., W.J. Brook, S.M. Cohen, and J.B. Bell. 1995. Distinguish able functions for engrailed and invected in anterior-posterior patterning in the Drosphila wing. Nature 376: 424-427.

Stewart, A.F., C.W. Richard III, J. Suzow, D. Stephan, S. Weremowicz, C.C. Morton, and C.N. Adra. 1996. Cloning of human RTEF-1, a transcriptional enhancer factor-1-related gene preferentially expressed in skeletal muscle: Evidence for an ancient multigene family. Genomics 36: 68-76.

Williams, J.A., J.B. Bell, and S.B. Carroll. 1991. Control of Drosphila wing and haltere development by the nuclear vestigial gene product. Genes \& Dev. 5: 2481-2495.

Williams, J.A., S.W. Paddock, and S.B. Carroll. 1993. Pattern formation in a secondary field: A hierarchy of regulatory genes subdivides the developing Drosphila wing disc into discrete subregions. Development 117: 571-584.

Williams, J.A., S.W. Paddock, K. Vorwerk, and S.B. Carroll. 1994. Organization of wing formation and induction of a wing-patterning gene at the dorsal/ventral compartment boundary. Nature 368: 299-305.

Xiao, J.H., I. Davidson, D. Ferrandon, R. Rosales, M. Vigneron, M. Macchi, F. Ruffenach, and P. Chambon. 1987. One cell-specific and three ubiquitous nuclear proteins bind in vitro to overlapping motifs in the domain B1 of the SV40 enhancer. EMBO J. 6: 3005-3013.

Xiao, J.H., I. Davidson, H. Matthes, J.M. Garnier, and P. Chambon. 1991. Cloning, expression, and transcriptional properties of the human enhancer factor TEF-1. Cell 65: 551-568.

Yockey, C.E., G. Smith, S. Izumo, and N. Shimizu. 1996. cDNA cloning and characterization of murine transcriptional enhancer factor-1-related protein 1, a transcription factor that binds to the M-CAT motif. J. Biol. Chem. 271: 3727-3736.

Zecca, M., K. Basler, and G. Struhl. 1996. Direct and long range action of a wingless morphogen gradient. Cell 87: 833-844. 


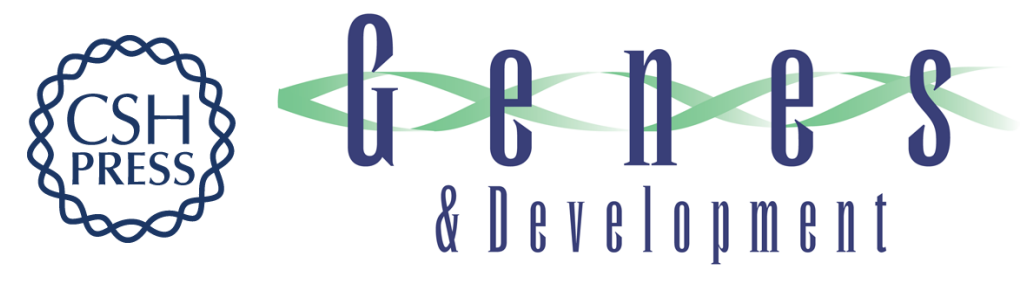

\section{Molecular interactions between Vestigial and Scalloped promote wing formation in Drosophila}

Andrew J. Simmonds, Xiaofeng Liu, Kelly H. Soanes, et al.

Genes Dev. 1998, 12:

Access the most recent version at doi:10.1101/gad.12.24.3815

References

This article cites 30 articles, 16 of which can be accessed free at: http://genesdev.cshlp.org/content/12/24/3815.full.html\#ref-list-1

\section{License}

Email Alerting

Receive free email alerts when new articles cite this article - sign up in the box at the top Service right corner of the article or click here.

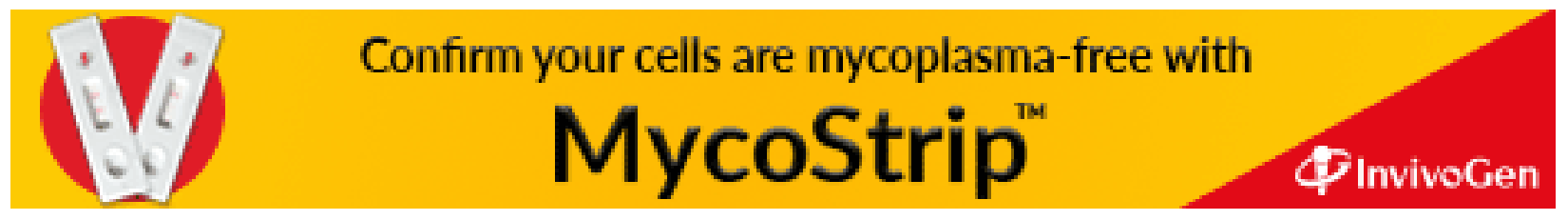

